\title{
Causes of Dimming and Brightening in China Inferred from Homogenized Daily Clear-Sky and All-Sky in situ Surface Solar Radiation Records (1958-2016)
}

\author{
SU YANG \\ National Meteorological Information Centre, China Meteorological Administration, Beijing, China, and ETH Zurich, \\ Institute for Atmospheric and Climate Science, Zurich, Switzerland \\ XiAOLAN L. WANG \\ Climate Research Division, Science and Technology Branch, Environment and Climate Change Canada, Toronto, Ontario, Canada \\ MARTIN WILD \\ ETH Zurich, Institute for Atmospheric and Climate Science, Zurich, Switzerland
}

(Manuscript received 5 October 2018, in final form 4 June 2019)

\begin{abstract}
This paper presents a study on long-term surface solar radiation (SSR) changes over China under clear- and all-sky conditions and analyzes the causes of the "dimming" and "brightening." To eliminate the nonclimatic signals in the historical records, the daily SSR dataset was first homogenized using quantile-matching (QM) adjustment. The results reveal rapid dimming before 2000 not only under all-sky conditions, but also under clear-sky conditions, at a decline rate of $-9.7 \pm 0.4 \mathrm{~W} \mathrm{~m}^{-2}$ decade $^{-1}$ (1958-99). This is slightly stronger than that under all-sky conditions at $-7.4 \pm 0.4 \mathrm{~W} \mathrm{~m}^{-2}$ decade $^{-1}$, since the clear-sky dimming stopped 15 years later. A rapid "wettening" of about 40-Pa surface water vapor pressure (SWVP) from 1985 to 2000 was found over China. It contributed $2.2 \%$ to the SSR decline under clear-sky conditions during the whole dimming period (1958-99). Therefore, water vapor cannot be the main cause of the long-term dimming in China. After a stable decade (1999-2008), an intensive brightening appeared under the clear-sky conditions at a rate of $10.6 \pm 2.0 \mathrm{~W} \mathrm{~m}^{-2} \mathrm{decade}^{-1}$, whereas a much weaker brightening $\left(-0.8 \pm 3.1 \mathrm{~W} \mathrm{~m}^{-2} \mathrm{decade}^{-1}\right)$ has been observed under all-sky conditions between 2008 and 2016. The remarkable divergence between clear- and allsky trends in recent decades indicates that the clouds played two opposite roles in the SSR changes during the past 30 years, by compensating for the declining SSR under the cloud-free conditions in 1985-99 and by counteracting the increasing SSR under cloud-free conditions in 2008-16. Aerosols remain as the main cause of dimming and brightening over China in the last 60 years, although the clouds counteract the effects of aerosols after 2000 .
\end{abstract}

\section{Introduction}

Surface solar radiation (SSR) is an important part of the global energy balance. It is the energy source for the general circulation and the water cycle. It influences the plant photosynthesis and carbon uptake, and determines, to a large extent, the climatic conditions on our planet (Muneer 2004; IPCC 2014; Shi 2007; Wild 2012).

Significant decadal changes in SSR have been found at widespread locations, with a decline since the 1950s and a subsequent increase starting in the 1980s (Wild et al. 2005;

Corresponding authors: Su Yang, yangsu@cma.gov.cn; Martin Wild,martin.wild@env.ethz.ch
Wild 2009, 2012; Pinker et al. 2005; Stanhill and Cohen 2001; Stanhill 2005). China's SSR records demonstrated similar characteristics (Shi et al. 2008; Yang et al. 2013; Qian et al. 2006; Tang et al. 2011; Wang and Wild 2016; He et al. 2018; Wang et al. 2012). These phenomena are well known as "global dimming" and "global brightening" (Wild et al. 2005; Wild 2009, 2012; Pinker et al. 2005; Stanhill and Cohen 2001; Stanhill 2005).

Efforts have been made to identify the reasons causing the SSR long-term trend and its reversal. It has been recognized that the availability of extended records under both clear- and all-sky conditions provides a unique opportunity to study separately the role of clouds on the one hand and the transparency of the cloud-free 
atmosphere on the other hand in the SSR changes. Based on the SSR data under clear- and all-sky conditions with 1-min time resolution from the Baseline Surface Radiation Network (BSRN; Ohmura et al. 1998), Wild et al. (2005) found that processes under both clear- and all-sky conditions contributed to the brightening during the 1990s, possibly pointing to an interplay of direct and indirect aerosol effects. Kumari and Goswami (2010) segregated daily SSR data into clearand cloudy-sky composites and discovered an aerosolinduced SSR decline in India at $\sim 6 \mathrm{~W} \mathrm{~m}^{-2}$ decade $^{-1}$ (cloud-free) from 1981-2006 while clouds nearly doubled the rate to $\sim 12 \mathrm{~W} \mathrm{~m}^{-2}$ decade $^{-1}$ (cloudy). On the basis of homogenized daily SSR data, Manara et al. (2016) found stronger SSR trends under clear-sky than all-sky conditions, especially during dimming (from the 1960s to the 1980s) and concluded that the aerosol radiative effect was to some extent masked by the clouds. Jahani et al. (2017) illustrated that the dimming in Iran since the 2000s is a combined effect of increased aerosol and cloud fraction, based on a comparison between clear- and all-sky trends. Qian et al. $(2006,2007)$ divided the SSR data (without homogenization) into clear-sky and all-sky data to analyze the effects of clouds, aerosol, and water vapor on the SSR long-term trend over China. Wang et al. (2009) established a global climatology of inverse visibilities under clear-sky conditions over land from 1973 to 2007 and interpreted it in terms of changes in aerosol optical depth and the consequent impacts on SSR. X. Yang et al. (2018) showed that decreasing trends of SSR induced by aerosols contributed to the decadal surface cooling during winter in Hong Kong during the last two decades, while there was still a warming trend in summer due to low loading and weak variation of aerosols.

SSR observations are sensitive to relocation and changes in observational instruments and schedules (Manara et al. 2016, 2017; Sanchez-Lorenzo et al. 2013, 2015; Hakuba et al. 2013; S. Yang et al. 2018). Many studies have pointed out serious temporal inhomogeneity issues in the Chinese historical SSR data (e.g., changes in the measurement times and environments, relocation, and instrument updates) resulting in misleading climate change results. Efforts to diminish the inhomogeneity have been made (Wang et al. 2013, 2015; S. Yang et al. 2018; Tang et al. 2011). Unfortunately, most of these studies focused on monthly data rather than on daily data, which are a necessary prerequisite for clear-sky analyses.

The main objective of this study is to study the temporal changes not only under all-sky conditions, but particularly also under clear-sky conditions over the period from 1958 to 2016, and to analyze the causes of the dimming and brightening based on the development of a homogenized daily SSR dataset over China. The

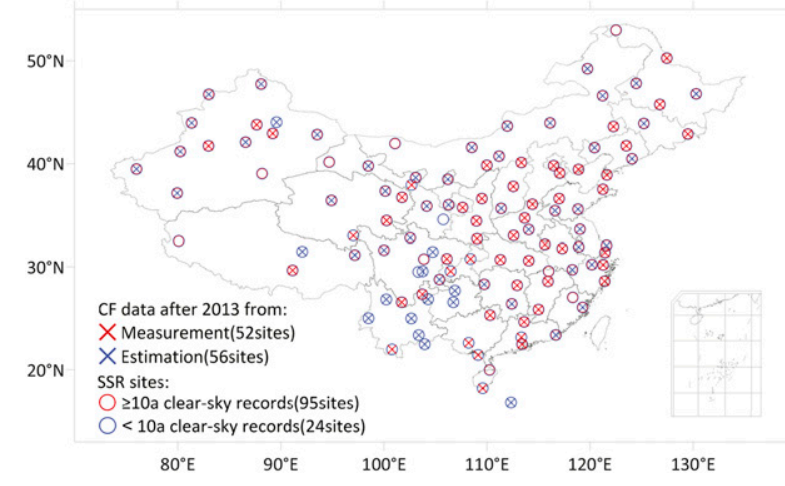

FIG. 1. Distribution of 119 SSR stations in China. The red and blue circles represent the sites with more and fewer than 10 years of SSR records under clear-sky conditions, respectively. The stations marked with red circles are used in this study. A cross in the circle stands for the method of the CF data obtained after 2013. The red crosses show continued CF observations after 2013; the blue crosses display discontinued CF observations after 2013, estimated from nearby stations; the circles without a cross represent stations with no suitable CF estimates after 2013.

dataset used in this study is described in section 2, where the clear-sky identification, the calculation of the annual and regional series, and the data homogenization method are also presented. The results of the long-term SSR trend analysis, including the national average SSR series under clear- and all-sky conditions for China, are shown and discussed in section 3. Finally, the conclusions of this study are presented in section 4 .

\section{Data and methods}

Daily SSR and cloud fraction (CF) data for 119 sites in China (Fig. 1), as well as the related metadata at Chinese routine weather stations, were released by the China Meteorological Administration (CMA), National Meteorological Information Center (NMIC), in 2013 and are updated every 1-2 months (http://data.cma.cn). Data quality-control procedures have been applied, including the spike value tests to remove the records that are higher than the SSR under clean air conditions (without cloud and aerosol) as derived from the Simple Model of Atmospheric Radiative Transfer of Sunshine (SMARTS) of Gueymard (2001), and the stuck value tests to identify and discard repetitive recordings of the same values in the data series. All data that pass the tests are classified as "credible"; the others are diagnosed further by experts at the stations and identified as "doubtful" or "wrong." Only the credible data, which account for about $95 \%$ of the data, are used in the present study. The surface water vapor pressure is calculated from homogenized surface daily temperature (Xu et al. 2013) and humidity datasets (Zhu et al. 2015), 
in which the dramatic shifts caused by nonclimatic influences in the historical records were eliminated. All daily SSR data have been homogenized to eliminate the nonclimatic changes in the historical records (section 2a). A less strict clear-sky definition (CF threshold) (section 2b) and improved annual and regional average calculation approaches (section 2c) have been used to obtain more samples and reduce the influence of limited sample size under clear-sky conditions, particularly for the humid regions and rainy seasons.

\section{a. Data homogenization}

S. Yang et al. (2018) used the RHtestsV4 software package (Wang and Feng 2013) and metadata to homogenize China's monthly SSR records. We also used this package to homogenize China's daily SSR records. The package has been widely used to alleviate historical data inhomogeneity issues (Vincent et al. 2002; Zhang et al. 2005; Wan et al. 2010; Dai et al. 2011; Wang et al. 2014). It includes a relative test for cases when highly related and good-quality data are available for use as reference series, as well as an absolute test that tests the candidate series directly when a suitable reference is not available. The relative test is based on the penalized maximal $t$ test (PMT; Wang et al. 2007) and is applied to the difference series between the candidate and the reference series. The absolute test is based on the penalized maximal $F$ test (PMF; Wang 2008) and was applied in this study to double-check the results. All tests are conducted at the 5\% significance level.

The homogenization of the daily SSR data was done in this study mainly based on the results of homogeneity tests applied to the corresponding monthly SSR data as done by S. Yang et al. (2018), who applied a relative test or absolute test to detect changepoints in monthly SSR records, depending on whether a reference series is available. They used neighboring surface sunshine duration (SD) data as reference data when available. A total of 159 changepoints detected by S. Yang et al. (2018) representing the months with inhomogeneity issues were first modified to the dates in accordance with metadata, and were then doublechecked using the RHtestsV4 software package. As a result, 122 out of the 159 changepoints were confirmed for the daily SSR series, and 37 changepoints were proven to be induced by gross errors and were eliminated by the quality control of the daily data. Here we also identified 53 additional changepoints, which were left unidentified in the monthly series due to the limited sample size and lack of metadata support, especially in recent years (after 2011).

For all changepoints that were determined to be significant artificial changepoints, the quantile-matching

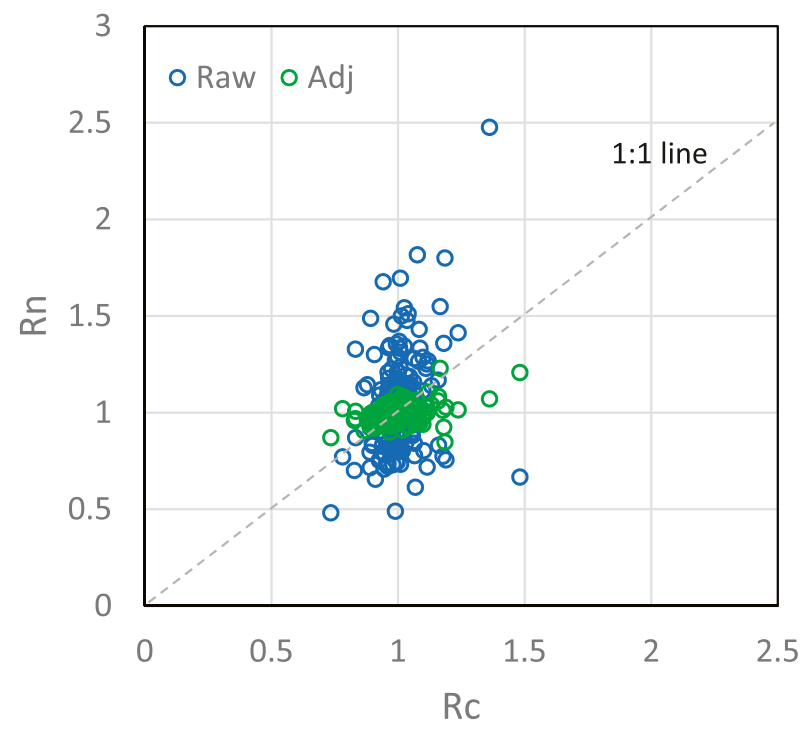

FIG. 2. Comparison of changes in SSR and SD before and after the changepoints. The blue and green circles represent the results obtained from the raw and adjusted SSR daily data, respectively. On the $x$ axis $R_{c}$ is the change in SSR level defined as the ratio between the SSR level (mean) for the 2 years before and after a changepoint. On the $y$ axis $R_{n}$ is similar to $R_{c}$ but for the average result of the nearby SD stations (all stations within a $250-\mathrm{km}$ radius).

(QM) adjustment method (Wang et al. 2010, 2014) without reference series is used to adjust the SSR data series to the latest segment. The objective of the QM adjustments is to adjust the base series so that the empirical probability distributions of all segments of the detrended base series match each other. The adjustment values were estimated from the detrended base series. The adjustment values depend on the empirical frequency of the data to be adjusted; namely, they vary from one value to another in the same segment, depending on their corresponding empirical frequencies.

As described in many studies (Manara et al. 2016, 2017; S. Yang et al. 2018; Wang et al. 2015), SD is highly correlated with SSR, showing good spatial consistency. Thus, the homogenization effects on the daily series are assessed by comparing the change in SSR with the corresponding change in SD averaged over the neighboring stations.

In Fig. $2, R_{c}$ is the change in SSR defined as the ratio of the average of daily SSR for the 2 years before a changepoint to the one for the 2 years after the changepoint. The term $R_{n}$ is similar to $R_{c}$ but is the ratio for the average result of the nearby SD stations [all stations within $250-\mathrm{km}$ radius that have good correlations with SSR of the candidate station generally (S. Yang et al. 2018) were used to calculate $R_{n}$ ]. Clearly, there are remarkable changes within a short time in the 
raw SSR daily data (blue circles), with $R_{c}$ ranging from 0.48 to 2.47 (sample volume for $R_{c}$ is 175 points) while the corresponding SD changes at nearby SD stations are minimal, with $R_{n}$ varying from 0.73 to 1.48 (same sample volume as $R_{c}$ ). The RMSE and absolute relative error between $R_{c}$ of the raw SSR data and $R_{n}$ reach $0.26 \%$ and $18.6 \%$, respectively. However, for the adjusted data, the $R_{c}$ and $R_{n}$ values are comparable, with all green circles distributed around the 1:1 line and $R_{c}$ varying from 0.74 to 1.48. The RMSE and absolute relative error between $R_{c}$ of the adjusted data and $R_{n}$ are $0.08 \%$ and $5.5 \%$, respectively, which are much lower than those of the raw data. All these results indicate that there are significant irregularities in the raw SSR data causing spatial inconsistencies. The SSR homogenization alleviates these issues effectively.

\section{b. Clear-sky identification}

In this study, the threshold of maximum CF to consider a day as cloud-free is set at $15 \%$, which is slightly higher than the commonly used level of $10 \%$ (Qian et al. 2006, 2007). The difference caused by using the slightly higher CF threshold was evaluated by comparing the monthly SSR climatology under different clear-sky thresholds $(10 \%$ and $15 \%)$ with the one under true cloud-free conditions $(0 \% \mathrm{CF})$. The average relative error of the monthly SSR climatology varies from $-0.7 \%$ (with $10 \%$ CF defined as clear sky) to $-1.2 \%$ (with $15 \%$ CF defined as clear sky), while the number of sites with at least 10 years of clear-sky data increases from 61 to 95 . That is, the new CF threshold barely reduces the representativeness of clear sky and provides more samples for this study. Thus, we chose to use the $15 \%$ threshold in this study.

It should be noted that although there used to be more than 2400 observatories monitoring CF in China, twothirds of them terminated this operation in 2013. Consequently, 67 out of 119 SSR sites no longer have CF data after 2013 (see Fig. 1). To resolve the issue of missing CFs after 2013, we estimated cloud cover using neighboring station data according to this formula:

$$
\mathrm{CF}^{\prime}=\frac{\sum_{j=1}^{3} \mathrm{CF}_{j} r_{j}}{\sum_{j=1}^{3} r_{j}},
$$

where $\mathrm{CF}^{\prime}$ denotes the estimated daily cloud fraction of the candidate station, $r_{j}$ is the correlation coefficient between the candidate station and its $j$ th highly correlated $\left(r_{j}>0.7\right)$ nearby site, which has the daily cloud fraction of $\mathrm{CF}_{j}$.
The performance of the estimated CF in the clear-sky identification is evaluated by the rate of misjudgments of clear-sky conditions defined as

$$
\begin{aligned}
& R_{\mathrm{mis}}=\frac{\sum n_{i}}{N},
\end{aligned}
$$

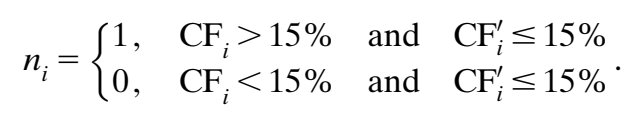

The subscript $i$ refers to the $i$ th day, $\mathrm{CF}$ and $\mathrm{CF}^{\prime}$ are measured and estimated $\mathrm{CF}$, respectively, and $N$ is the number of days. The threshold of clear-sky CF is set as $15 \%$. We retained and used only the estimated cloud cover with $R_{\text {mis }} \leq 15 \%$ in this study.

Figure 1 shows the availability of CF data at the 119 SSR stations after 2013. We were able to obtain suitable estimates of CF for 56 out of the 67 sites where CF observation was terminated in 2013 (see blue crosses in Fig. 1). For the other 11 stations (circles without the cross), we could not obtain reliable CF estimates due to too-few neighboring clear-sky data that can be used for the estimation.

\section{c. Annual and regional series calculation}

SSR in China shows a notable seasonal cycle. It is determined by the changes in the insolation at the top of the atmosphere (TOA) and the atmospheric transmittance. The ideal annual clear-sky series should include each month of the year, but there are fewer clear-sky samples in summer (June-August) than in the other seasons because of the Asian monsoon climate and associated cloudiness (Ding and Chan 2005; Chang 2004; Shi and Xu 2006; Li et al. 2016).

The feasibility of calculating the annual series based on seasonal series rather than monthly series is evaluated. We use the clear-sky index (CSI; the ratio between the measured SSR and the insolation at the TOA) to evaluate the consistency in monthly SSR because it removes the effect of the varying solar radiation received at the TOA and stands for the relative SSR independent of the incident radiation level at the TOA. Figure 3 illustrates the comparisons of CSI between different months. The circles in Fig. 3 represent long-term averages of monthly CSI under cloud-free conditions at 119 stations. It is obvious that there is a significant seasonal variation of the CSI in China. The CSI in the months representing summer conditions (June and July) is lower than that in the months representing winter (January and February), whereas a high coherence can be found in the summer and winter seasons. This implies that it is possible to calculate the annual series based on the seasonal series only if there is no 

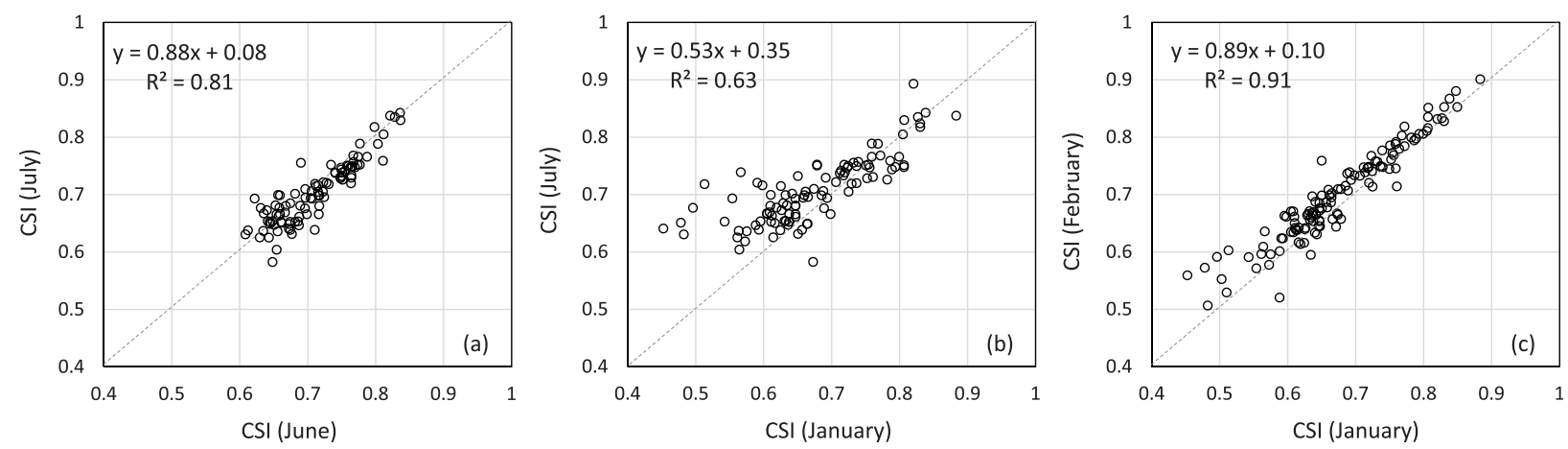

FIG. 3. Comparison of climatological CSI (the ratio between the measured daily SSR and the insolation at TOA) identified at 119 stations between different months: (b) comparison of CSI between summer (July) and winter (January), and correspondence of CSI in the (a) summer (June and July) and (c) winter (January and February).

missing seasonal value in the year. Otherwise, this can introduce significant biases.

Based on these results, the annual SSR series of each site was calculated in this study as follows:

1) Calculate the daily CSI and select the days with $\mathrm{CF}$ lower than $15 \%$ as the clear-sky data.

2) Obtain seasonal CSI data if there are at least five clearsky days within the season, and convert them to seasonal SSR series by multiplying with the seasonal mean incident radiation at the TOA. The annual series is then the average of the four seasonal SSR series.

3) The years without clear-sky data are also treated as missing in the all-sky series to remove the influence of different sample sizes on the comparison between SSR under clear- and all-sky conditions.

As a result, there are 95 stations with clear-sky SSR series exceeding 10 years (red circles in Fig. 1), which were used in this study. They almost cover the whole country, with fewer sites in the southwestern and southern regions because of the humid and cloudy climate (Ding and Chan 2005; Chang 2004; Shi and Xu 2006).

The calculation of the regional average series was done in this study as follows:

1) Obtain the grid box average SSR value for each $5^{\circ} \times$ $5^{\circ}$ grid box, using the first difference method (FDM) (Peterson and Easterling 1994), which has been proven to be suitable for an irregular observation network with diverse record lengths, as well as starting and ending times, and which is able to use the maximum station density for the calculation of longterm changes. The formulas for calculating the FDM average SSR series for each box are given as follows:

$$
\mathrm{FDM}_{n-i}^{j}=\mathrm{SSR}_{n-i+1}^{j}-\mathrm{SSR}_{n-i}^{j}
$$

$$
\begin{aligned}
\overline{\operatorname{SSR}}_{n} & =\operatorname{mean}\left(\mathrm{SSR}_{n}^{j}\right), \\
\overline{\mathrm{FDM}}_{n-i} & =\operatorname{mean}\left(\mathrm{FDM}_{n-i}^{j}\right), \\
\overline{\mathrm{SSR}}_{n-i} & =\overline{\operatorname{SSR}}_{n}+\overline{\mathrm{FDM}}_{n-i},
\end{aligned}
$$

for $i=1,2, \ldots, n-1$ and $j=1,2, \ldots, m-1, m$. SSR and FDM are the surface solar radiation record and first difference series of each station, respectively; $\bar{X}$ denotes the average of $X$ over a grid box; subscript $i$ denotes the $i$ th year; superscript $j$ denotes the $j$ th station falling in the grid box; and $n$ and $m$ stand for the length of series and the number of stations in the box, respectively.

2) Calculate the regional SSR FDM series and the regional average SSR of the last year by area-weighted averaging of the FDM series and SSR records of the last year over all grid boxes that contain data over the region.

3) Translate the regional average FDM series into SSR series by (7) and obtain the SSR anomaly series by subtracting the mean of the reference period 1961-90.

This regional averaging method is similar to the one used by S. Yang et al. (2018). Here, the recovery of regional SSR series from FDM series was done at the last step. Thus the regional series includes all gridded FDM series regardless of the climatological mean value during the specific reference period. The grids that have SSR observation after the reference period for anomaly series calculation (1961-90) could be utilized in this study.

\section{Results}

\section{a. Clear- and all-sky SSR long-term trends}

Figure 4 displays the area-weighted average SSR anomaly series over China for the period $1958-2016$ as 


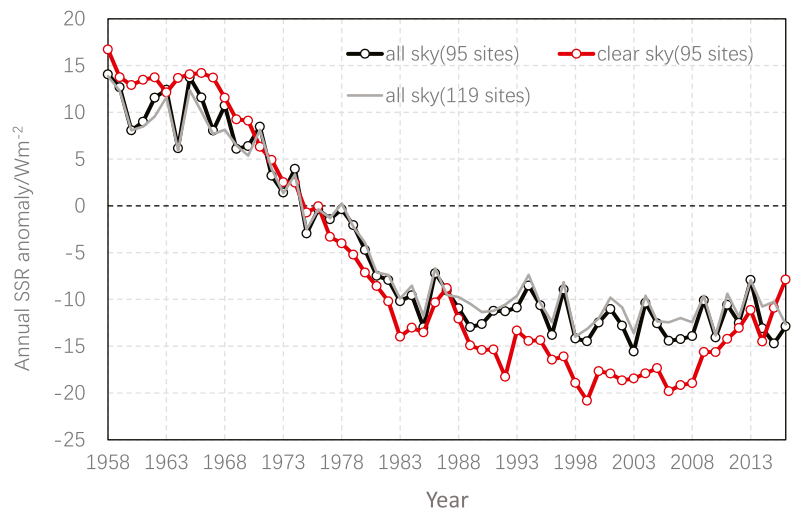

FIG. 4. Area-weighted average SSR anomaly series over China for the period 1958-2016 as derived under all-sky (black and gray lines) and clear-sky (red line) conditions. The reference period for the determination of the anomalies is 1961-90. Black and gray curves refer respectively to the result derived from all SSR observations (119 sites; all circles in Fig. 1) and the result obtained from those 95 sites that have at least 10 years of records under clear-sky conditions (red circles in Fig. 1), i.e., the same sample size as used in the calculation of clear-sky series.

derived under all-sky and clear-sky conditions. Both gray and black curves are all-sky SSR anomaly series, but the gray curve stands for the result derived from all SSR observations (119 sites; all circles in Fig. 1), while the black one was obtained from those 95 sites that have at least 10 years of data under clear-sky conditions, that is, the same sample size as used in the calculation of clear-sky series (red line in Fig. 1). The gray and black curves show very small differences, which suggests that the change from 119 to 95 sites barely affects the Chinese SSR anomaly series. The results from the 95 sites also well represent the SSR change over China.

Irrespective of the presence or absence of clouds, China experienced surface solar dimming from 1958 to 1985 . The decline rates reach $-11.9 \pm 0.6$ and $-9.2 \pm 0.7 \mathrm{~W} \mathrm{~m}^{-2}$ decade $^{-1}$ for clear sky and all sky, respectively (Table 1 ). The total reduction in SSR over the 28 years is about 26 and $21 \mathrm{~W} \mathrm{~m}^{-2}$ for clear sky and all sky, respectively (determined as the difference between the averages over the first and the last 5 years of the period). A remarkable divergence between the clear-sky (red curve) and all-sky (black curve) time series appears after 1985. The red curve (clear sky) decreases continually until 1999 and begins to increase after a stable decade from 1999 to 2008. The total decrease in SSR under clear sky from 1958 to 1999 comes up to around $31 \mathrm{~W} \mathrm{~m}^{-2}$ followed by a recovery of about $6 \mathrm{~W} \mathrm{~m}^{-2}$ from 2008 to 2016 (determined as the difference between the averages over the first and the last 4 years of the period). The declining (1958-99) and rising
TABLE 1. Decadal trends of the Chinese area-weighted average SSR anomaly time series $\left(\mathrm{W} \mathrm{m}^{-2}\right.$ decade $^{-1}$ ) under all-sky (black line in Fig. 4) and clear-sky (red line in Fig. 4) conditions for six different periods. An asterisk indicates trends with at least $5 \%$ significance.

\begin{tabular}{lcc}
\hline \hline \multicolumn{1}{c}{ Period } & All sky & Clear sky \\
\hline $1958-2016$ & $-4.9 \pm 0.3^{*}$ & $-6.1 \pm 0.5^{*}$ \\
$1958-85$ & $-9.2 \pm 0.7^{*}$ & $-11.9 \pm 0.6^{*}$ \\
$1958-99$ & $-7.4 \pm 0.4^{*}$ & $-9.7 \pm 0.4^{*}$ \\
$1985-2016$ & $-0.7 \pm 0.4$ & $-0.2 \pm 0.6$ \\
$1985-99$ & $-2.6 \pm 1.3$ & $-5.4 \pm 1.2^{*}$ \\
$2008-16$ & $-0.8 \pm 3.1$ & $10.6 \pm 2.0^{*}$ \\
\hline
\end{tabular}

(2008-16) rates are $-9.7 \pm 0.4$ and $10.6 \pm 2.0 \mathrm{Wm}^{-2}$ decade $^{-1}$, respectively (Table 1 ). In the meantime, the black curve (all sky) remains at nearly the same mean level in the last 30 years (1985-2016), with a small change rate of $-0.7 \pm 0.4 \mathrm{~W} \mathrm{~m}^{-2}$ decade $^{-1}$ over this period (Table 1). This slightly differs from the all-sky time series we previously published (S. Yang et al. 2018) due to improvements in data quality control, homogenization, and the calculation of the regional series (details in section 2). It is interesting to see that although the SSR under clear- and all-sky conditions differ in their evolution during the last 30 years, the recent SSR levels under either clear- or all-sky conditions are close to those in the early 1980s.

The key message here is that the similar trends under clear- and all-sky conditions before the 1980s suggest that the changes in atmospheric transmittance in the cloud-free atmosphere dominate the change in Chinese SSR in this period. However, in more recent years, the brightening only appeared under clear-sky conditions but not under all-sky conditions, indicating that the clouds tend to counteract the increased SSR owing to the improvement in atmospheric transmittance, which results in a near-stable SSR level.

Figure 5 shows the decadal trends of the Chinese areaweighted average SSR anomaly time series given in Fig. 4 for different periods. The left and right panels show for the results obtained from the all-sky and clearsky SSR time series, respectively. The $x$ axis and $y$ axis indicate the starting and ending years of the period of the trend, respectively. The minimum length of the period is 8 years. The Chinese SSR decline rate under all-sky conditions during the dimming period ranges from -15.0 to $-1.0 \mathrm{~W} \mathrm{~m}^{-2}$ decade $^{-1}$. Thus, the maximal decline is much stronger than the one observed in Europe (Wild 2009; Sanchez-Lorenzo et al. 2013, 2015); while the subsequent upward trend in the brightening period is around $1.0-2.5 \mathrm{~W} \mathrm{~m}^{-2}$ decade $^{-1}$, the maximal upward trend is weaker than the brightening trend in Europe $\left(1.0-4.0 \mathrm{~W} \mathrm{~m}^{-2}\right.$ decade $^{-1}$; Sanchez-Lorenzo 

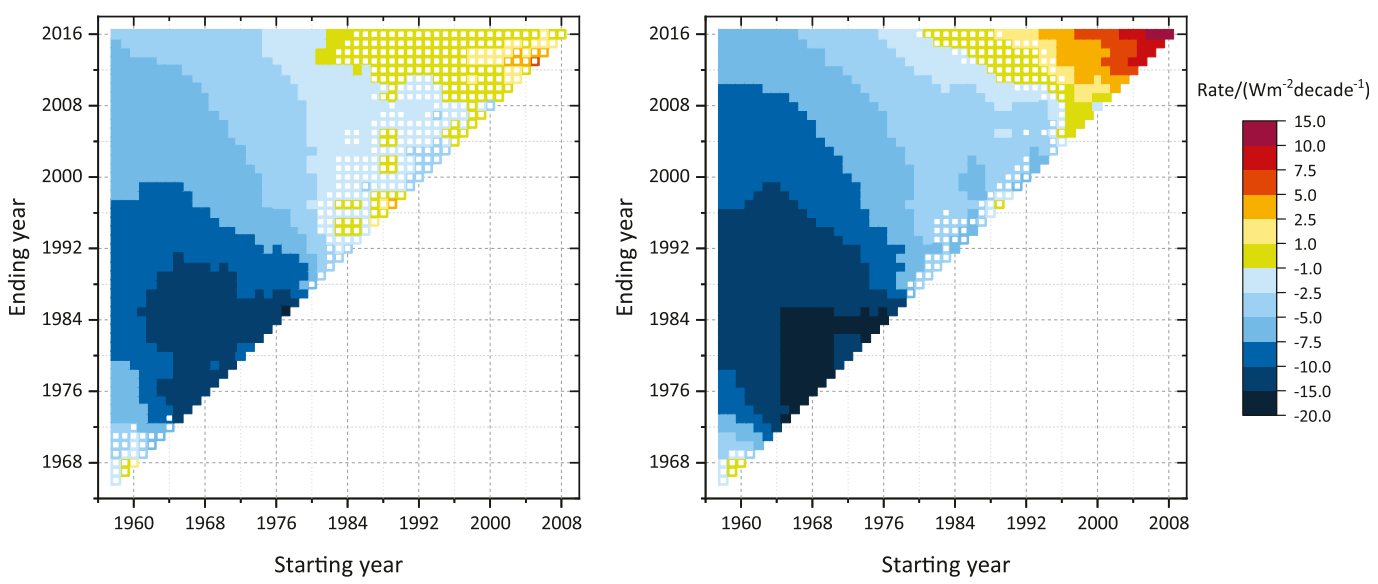

FIG. 5. The decadal trends of the Chinese area-weighted annual average SSR anomaly time series $\left(\mathrm{W} \mathrm{m}^{-2}\right.$ decade $^{-1}$ ) shown in Fig. 1 for different periods. Panels show results of (left) all-sky (black curve in Fig. 1) and (right) clear-sky (red curve in Fig. 1) time series. The $x$ axis and $y$ axis stand for the start and end years of the period of the trends, respectively. Solid squares represent a trend with at least $5 \%$ significance.

et al. 2015). Figure 5 (left) illustrates that the dimming disappeared gradually after 1980 , and there was no significant brightening following it. Compared with the all-sky panel, the clear-sky panel (Fig. 5, right) demonstrates a quicker SSR decline rate before 1990, varying from -20 to $-1.0 \mathrm{~W} \mathrm{~m}^{-2}$ decade $^{-1}$, and a stronger increasing trend after the early 2000s, ranging from 1 to $10 \mathrm{~W} \mathrm{~m}^{-2}$ decade $^{-1}$. The conversion from dimming to brightening is much more distinct, and the trends in most of the boxes are more intensive and significant, particularly for the recent two decades. This suggests that the clouds tend to weaken the cloud-free SSR change over most of the last 58 years, and nearly completely mask the clear-sky brightening seen in recent years.

Figure 6 displays the SSR trends at each site derived under all-sky and clear-sky conditions during different periods. Nearly all stations experienced significant dimming from 1960 to 1985 under both all-sky and clearsky conditions (Figs. 6a,d). The decline rate under clear sky is stronger than that under all sky at most of the sites. In Fig. $6 \mathrm{~d} 51.5 \%$ of sites show a quick decrease in SSR $\left(\leq-10 \mathrm{~W} \mathrm{~m}^{-2}\right.$ decade $\left.^{-1}\right)$, whereas this value is only $29.7 \%$ in Fig. 6a. In the following 15 years (1985-99), $19.3 \%$ of sites began to brighten significantly under allsky conditions, while the percentage under clear sky is $7.0 \%$. Most of the sites in Fig. $6 \mathrm{~b}$ show either more intensive brightening or weaker dimming than that in Fig. 6e, suggesting that the clouds extinguish less SSR in this period than before and induce the divergence of Chinese SSR series between clear and all sky in 1985-99 (Fig. 4). This situation reversed in the recent decade (2008-16): the clouds tend to mask the brightening trend under the cloud-free conditions, with fewer sites with significantly and strongly $\left(\geq 10 \mathrm{~W} \mathrm{~m}^{-2}\right.$ decade $\left.^{-1}\right)$ increasing SSR seen in Fig. 6c (21.5\%) than in Fig. 6f $(38.0 \%)$, especially for the southeastern region where trends under clear- and all-sky conditions are often of opposite signs (Figs. 6c,f).

\section{$b$. The contribution of the increased water vapor}

Aerosols are regarded as one of the most important radiative forcing factors and the major cause of SSR changes under clear-sky conditions (Qian et al. 2007; Wild 2012; Wang et al. 2012; Tang et al. 2010; Wang and Wild 2016; Norris and Wild 2009; Yang et al. 2016a,b; X. Yang et al. 2018). Water vapor is also an important radiative forcing factor (Cess 1974; Forster et al. 2007). Despite the fact that the absorbing radiative effect of water vapor in shortwave is weaker than in longwave radiation, it is still necessary to evaluate its influence on the detected SSR changes in China, considering the rapid increase of water vapor in the atmosphere over China in recent decades (Qian et al. 2007).

Figure 7 shows the area-weighted average surface water vapor pressure (SWVP) anomaly series over China for the period 1958-2016 on annual and summer- and winter-mean bases with respect to 1961-90 based on the sites labeled as red circles in Fig. 1. There is barely a seasonal difference and major changes in SWVP are only seen between 1985 and 2000 with a rapid "wettening" of 40-Pa SWVP, which exactly matches with the continuous dimming period under clear skies in the last 15 years of the twenty-first century. Thus, it can be concluded that the water vapor is 

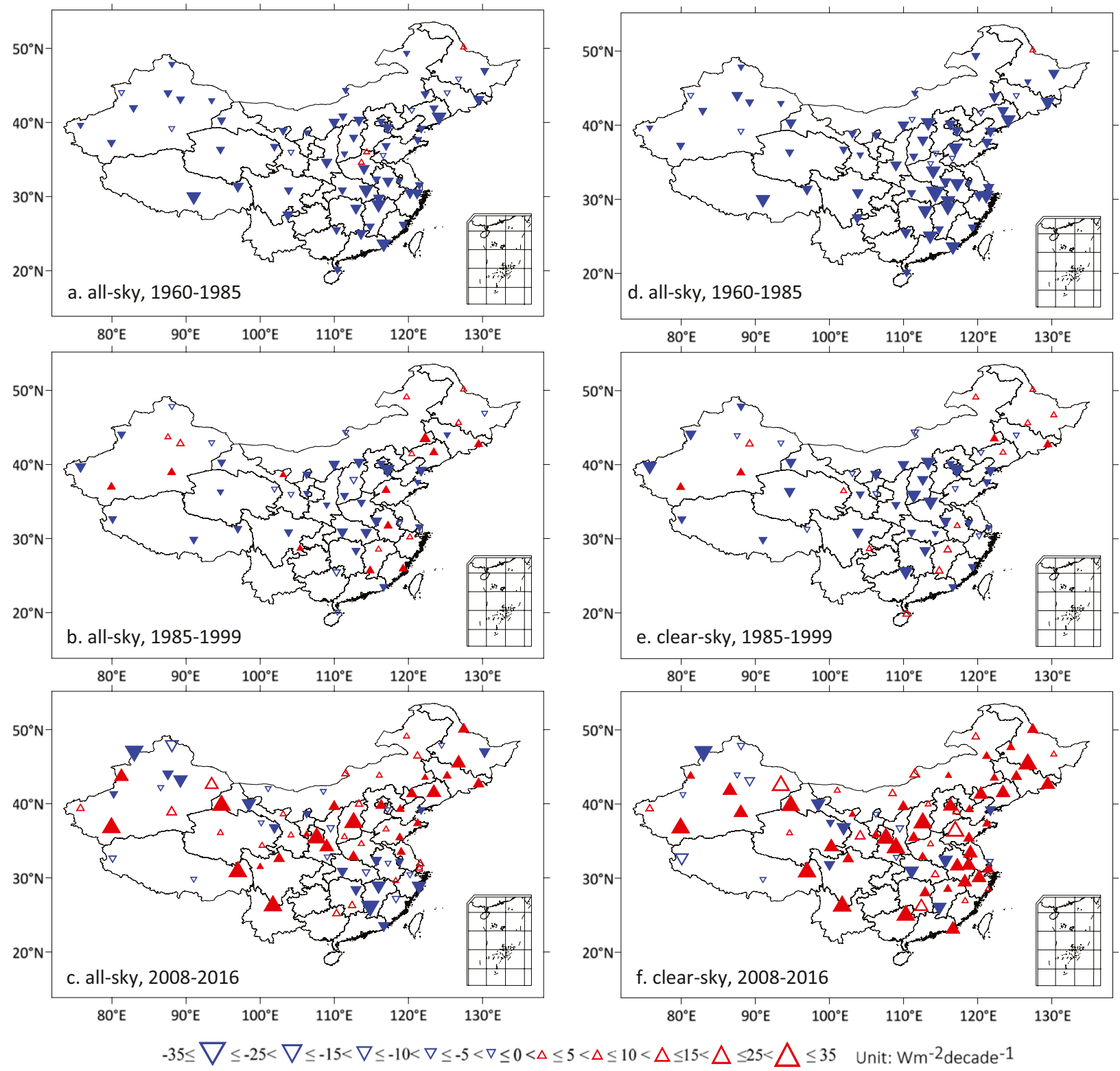

FIG. 6. Geographical distribution of trends at SSR stations as estimated under (a)-(c) all-sky and (d)-(f) clear-sky conditions during (top) 1960-85, (middle) 1985-99, and (bottom) 2008-16. The blue and red triangles stand for downward and upward trends, respectively. The triangle sizes are proportional to absolute change rates. Filled triangles indicate trends with at least $5 \%$ significance.

unrelated to the dimming before 1985 and the brightening after 2008 due to its only marginal change during these periods, but it contributes to the decline of SSR during 1985-99.

The radiative effect caused by the increasing SWVP is estimated by a radiative transfer model, namely the Simple Model of Atmospheric Radiative Transfer of Sunshine (SMARTS) developed by Gueymard (2001). The algorithms used by SMARTS were developed to match the output from the MODTRAN 4.0 (Berk et al.
1999) complex band models within $2 \%$. The results show that increasing SWVP by about $40 \mathrm{hPa}$ in the model (corresponding to the increase between 1985 and 2000) induces a change of $-0.69 \mathrm{~W} \mathrm{~m}^{-2}$ in SSR, accounting for about $10.0 \%$ of the SSR decrease $\left(-6.9 \mathrm{~W} \mathrm{~m}^{-2}\right)$ under clear-sky conditions over the dimming period of the last 15 years and about $2.2 \%$ of the total SSR decline under clear sky during the whole dimming period under clearsky conditions $\left(31 \mathrm{~W} \mathrm{~m}^{-2}\right.$, the decrease in SSR between 1958 and 2000). 


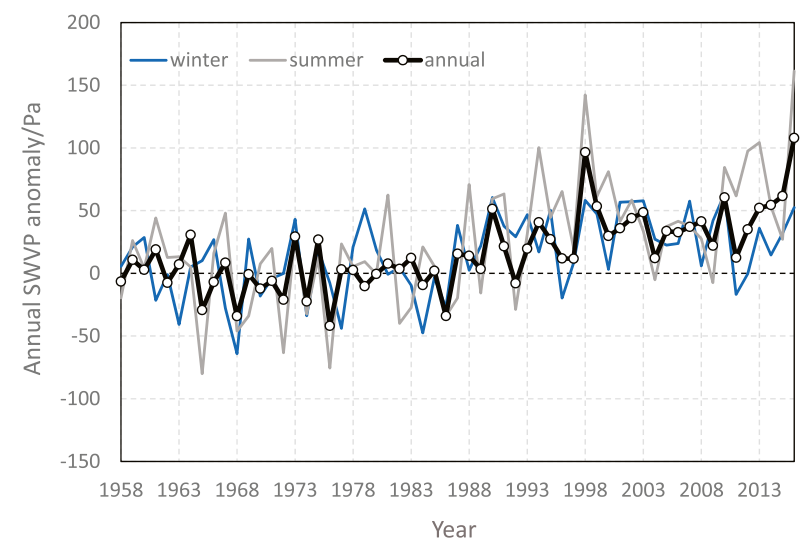

FIG. 7. The area-weighted average SWVP anomaly series over China for the period 1958-2016 based on 95 stations collocated with the SSR stations used in this study. The reference period is 1961-90.

Figure 8 shows the water vapor influence on changes in SSR at individual stations during the steadily increasing period of surface water vapor (1985-2000, in Fig. 7). The triangles in Fig. 8 are calculated by the SMART model, representing the estimated differences between SSR in 1985 and 2000 (5-yr smoothing average), which are only influenced by the variation of SWVP. It can be found that during this period the increases in water vapor over China contributed to a largescale dimming, and the western region shows stronger dimming than that in the eastern region. However, the contribution from water vapor to the SSR changes are on small: from about -1.5 to $-0.5 \mathrm{~W} \mathrm{~m}^{-2}$.

These results indicate that the water vapor contributes to the dimming to a small extent, but it cannot be the main cause of long-term dimming over China. Aerosols, which have been deemed to be among the most influential factors in the changing Earth's energy balance, particularly in the shortwave (IPCC 2014; Yu et al. 2006), and have experienced significant changes over China (Wu et al. 2014; Sogacheva et al. 2018; de Leeuw et al. 2018), are thus left as major suspects of causing the identified dimming and brightening under cloud-free conditions in China in the last 60 years.

It should be noted that the short wavelength radiative effects of water vapor in this study were estimated from the surface measurements of relative humidity. Although a previous study has pointed out the possibility of using surface humidity measurements as proxy data for integrated water vapor (Ruckstuhl et al. 2007), there is no doubt that the application of water vapor profiles e.g., from radiosonde or global positioning system (GPS) (Bevis et al. 1992) measurements could further refine our above estimate of the shortwave radiative effect of water vapor.

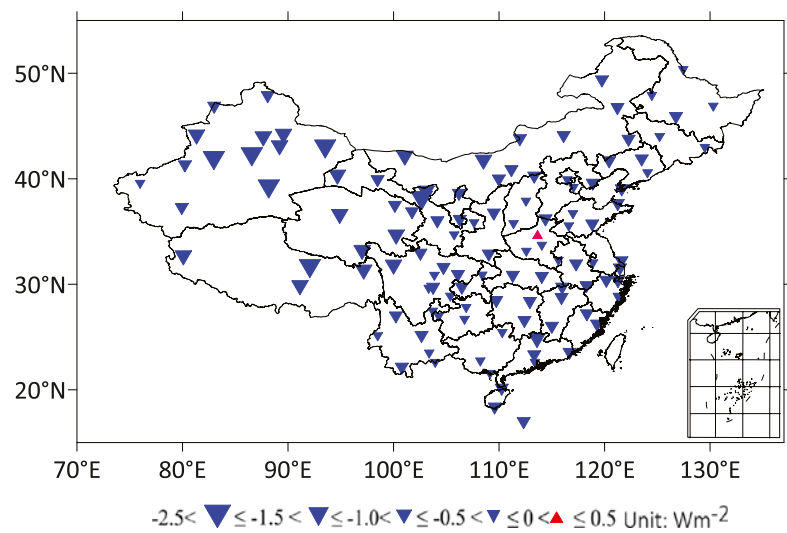

FIG. 8. The model-estimated changes in SSR at individual sites caused solely by the steady increase in water vapor from 1985 to 2000 .

\section{Summary and discussion}

In this study, we have applied a procedure to homogenize China's daily SSR data and used the homogenized data to assess the SSR trends specifically under clear-sky conditions over the period 1958-2016. Compared to our previous study focusing on the homogenization of monthly SSR data (S. Yang et al. 2018), 37 changepoints caused by gross errors are eliminated through the efforts in the quality control of the daily data, and 53 new changepoints were identified, which were not identified in the monthly series due to limited sample size, especially in recent years (after 2011) where metadata are not available.

Irrespective of the presence or absence of clouds, China experienced surface dimming from 1958 to 1985. This is followed by a remarkable divergence between clear- and all-sky conditions: the dimming continued in the next 15 years only under clear-sky conditions, whereas there is no noticeable SSR change under allsky conditions. In addition, an intensive brightening appeared in the recent decade (2008-16) under cloudfree conditions, which is not discernable under all-sky conditions. This indicates that clouds played two opposite roles in the SSR change in the most recent 30 years: compensating for the reduced SSR under cloud-free conditions in 1985-99 and counteracting the increasing SSR under cloud-free conditions in 2008-16.

The remarkable SSR changes under clear-sky conditions indicate that the atmospheric transmittance over China kept decreasing from 1958 to 1999 and began to recover after 2008. A rapid wettening by about $40-\mathrm{Pa}$ SWVP (surface water vapor pressure) over China is found during 1985-2000, which matches exactly with the continuous dimming period under the clear-sky conditions in the last 15 years of the twentieth century. 
We estimate that the wettening from 1985 to 2000 contributed about $10.0 \%$ to the SSR decline in this period but is not the main cause of the long-term clear-sky SSR changes in China. Thus aerosols remain as the main possible cause of dimming and brightening under cloud-free conditions. Therefore our results suggest that the aerosol loadings in China had been increasing before 2000 and started to decline around 2008. This conclusion is also in line with aerosol studies over China based on either in situ (Wu et al. 2014) or remote sensing observations (Sogacheva et al. 2018; Zheng et al. 2018). Their findings pointed out that aerosol optical depth (AOD) had been increasing before the 2000s and began to decrease after that, in line with our results. Their turning point matches well with the one of the clear-sky SSR series presented here.

It is interesting to find that clouds have nearly masked the brightening under clear-sky conditions in the recent decade, whereas clouds weakened the radiative effect and compensated for the reduced SSR caused by increasing aerosols in the dimming period (before 2000). It seems that the cloud radiative effects may be related to the aerosols. The clouds began to extinguish more solar radiation when the aerosol load over China turned to decline (Wu et al. 2014; Sogacheva et al. 2018; Zheng et al. 2018). Aerosol indirect and semidirect effects (Qiu et al. 2017; Zhao et al. 2012, 2018; Garrett and Zhao 2006; Zhao and Garrett 2015; McFarquhar et al. 2011; Johnson 2003; Zhou et al. 2017; Kudzotsa et al. 2016a,b; Koren et al. 2008; Feingold 2005; Koch and Del Genio 2010; Allen and Sherwood 2010; Brioude et al. 2009; Fan et al. 2008; Haywood and Boucher 2000; Lohmann and Lesins 2002; Quaas et al. 2010; Lohmann and Feichter 2005; Albrecht 1989) are supposed to play an important role.

The results inferred in the present study on the respective roles of aerosols and clouds in solar radiation received at Earth's surface over the recent 58 years may provide a reference for the assessment of the performance of climate models over China. The aerosol indirect and semidirect effects have not been the focus of this paper. More efforts are needed to constrain these, including applying more detailed clouds and aerosols information retrieved from satellites such as CloudSat (Stephens et al. 2002), CALIPSO (Winker et al. 2009), and AIRS (Aumann et al. 2003), as well as from in situ stations such as BSRN (Ohmura et al. 1998) and model simulations such CMIP6 (Eyring et al. 2016).

Acknowledgments. This work is supported by the National Natural Science Foundation of China (Grant 41805128), National Key R\&D Program of China (Grant
2017YFA0603502), the National Innovation Project for Meteorological Science and Technology (Quality Control, Fusion, and Reanalysis of Meteorological Observations, under Grant CMAGGTD003-5) and the China Scholarship Program (Grant 201605330025). Dimming and brightening research at ETH Zurich is supported by the Swiss National Science Foundation Grant 20002.159938/1 (Towards an improved understanding of the global energy balance: Temporal variations of solar radiation in the climate system).

\section{REFERENCES}

Albrecht, B. A., 1989: Aerosols, cloud microphysics, and fractional cloudiness. Science, 245, 1227-1230, https://doi.org/10.1126/ science.245.4923.1227.

Allen, R. J., and S. C. Sherwood, 2010: Aerosol-cloud semi-direct effect and land-sea temperature contrast in a GCM. Geophys. Res. Lett., 37, L07702, https://doi.org/10.1029/2010GL042759.

Aumann, H. H., and Coauthors, 2003: AIRS/AMSU/HSB on the Aqua mission: Design, science objectives, data products, and processing systems. IEEE Trans. Geosci. Remote Sens., 41, 253-264, https://doi.org/10.1109/TGRS.2002.808356.

Berk, A., and Coauthors, 1999: MODTRAN4 radiative transfer modeling for atmospheric correction. Proc. SPIE, 3756, 348 353, https://doi.org/10.1117/12.366388.

Bevis, M., S. Businger, T. A. Herring, C. Rocken, R. A. Anthes, and R. H. Ware, 1992: GPS meteorology: Remote sensing of atmospheric water vapor using the global positioning system. J. Geophys. Res., 97, 15 787-15801, https://doi.org/10.1029/ 92JD01517.

Brioude, J., and Coauthors, 2009: Effect of biomass burning on marine stratocumulus clouds off the California coast. Atmos. Chem. Phys., 9, 8841-8856, https://doi.org/10.5194/acp-9-88412009.

Cess, R. D., 1974: Radiative transfer due to atmospheric water vapor: Global considerations of the earth's energy balance. J. Quant. Spectrosc. Radiat. Transfer, 14, 861-871, https:// doi.org/10.1016/0022-4073(74)90014-4.

Chang, C.-P., 2004: East Asian Monsoon. World Scientific, 572 pp., https://www.worldscientific.com/doi/abs/10.1142/5482.

Dai, A., J. Wang, P. W. Thorne, D. E. Parker, L. Haimberger, and X. L. Wang, 2011: A new approach to homogenize daily radiosonde humidity data. J. Climate, 24, 965-991, https:// doi.org/10.1175/2010JCLI3816.1.

de Leeuw, G., and Coauthors, 2018: Two decades of satellite observations of AOD over mainland China using ATSR-2, AATSR and MODIS/Terra: Data set evaluation and largescale patterns. Atmos. Chem. Phys., 18, 1573-1592, https:// doi.org/10.5194/acp-18-1573-2018.

Ding, Y., and J. C. L. Chan, 2005: The East Asian summer monsoon: An overview. Meteor. Atmos. Phys., 89, 117-142, https:// doi.org/10.1007/s00703-005-0125-z.

Eyring, V., S. Bony, G. A. Meehl, C. A. Senior, B. Stevens, R. J. Stouffer, and K. E. Taylor, 2016: Overview of the Coupled Model Intercomparison Project Phase 6 (CMIP6) experimental design and organization. Geosci. Model Dev., 9, 19371958, https://doi.org/10.5194/gmd-9-1937-2016.

Fan, J., R. Zhang, W.-K. Tao, and K. I. Mohr, 2008: Effects of aerosol optical properties on deep convective clouds and 
radiative forcing. J. Geophys. Res., 113, D08209, https:// doi.org/10.1029/2007JD009257.

Feingold, G., 2005: On smoke suppression of clouds in Amazonia. Geophys. Res. Lett., 32, L02804, https://doi.org/10.1029/2004GL021369.

Forster, P., and Coauthors, 2007: Changes in atmospheric constituents and in radiative forcing. Climate Change 2007: The Physical Science Basis, S. Solomon et al., Eds., Cambridge University Press, 129-234.

Garrett, T. J., and C. Zhao, 2006: Increased Arctic cloud longwave emissivity associated with pollution from mid-latitudes. $\mathrm{Na}$ ture, 440, 787-789, https://doi.org/10.1038/nature04636.

Gueymard, C. A., 2001: Parameterized transmittance model for direct beam and circumsolar spectral irradiance. Sol. Energy, 71, 325-346, https://doi.org/10.1016/S0038-092X(01)00054-8.

Hakuba, M. Z., A. Sanchez-Lorenzo, D. Folini, and M. Wild, 2013: Testing the homogeneity of short-term surface solar radiation series in Europe. AIP Conf. Proc., 1531, 700-703, https:// doi.org/10.1063/1.4804866.

Haywood, J., and O. Boucher, 2000: Estimates of the direct and indirect radiative forcing due to tropospheric aerosols: A review. Rev. Geophys., 38, 513-543, https://doi.org/10.1029/ 1999RG000078.

He, Y., K. Wang, C. Zhou, and M. Wild, 2018: A revisit of global dimming and brightening based on the sunshine duration. Geophys. Res. Lett., 45, 4281-4289, https://doi.org/10.1029/ 2018 GL077424.

IPCC, 2014: Climate Change 2013: The Physical Science Basis. T. F. Stocker et al., Eds., Cambridge University Press, 1535 pp.

Jahani, B., Y. Dinpashoh, and M. Wild, 2017: Dimming in Iran since the 2000s and the potential underlying causes. Int. J. Climatol., 38, 1543-1559, https://doi.org/10.1002/joc.5265.

Johnson, B. T., 2003: The semi-direct aerosol effect. Ph.D. thesis, University of Reading, 201 pp., http://www.met.rdg.ac.uk/ phdtheses/The Semi-Direct Aerosol Effect.pdf.

Koch, D., and A. D. Del Genio, 2010: Black carbon semi-direct effects on cloud cover: Review and synthesis. Atmos. Chem. Phys., 10, 7685-7696, https://doi.org/10.5194/acp-10-7685-2010.

Koren, I., J. V. Martins, L. A. Remer, and H. Afargan, 2008: Smoke invigoration versus inhibition of clouds over the Amazon. Science, 321, 946-949, https://doi.org/10.1126/science.1159185.

Kudzotsa, I., and Coauthors, 2016a: Aerosol indirect effects on glaciated clouds. Part I: Model description. Quart. J. Roy. Meteor. Soc., 142, 1958-1969, https://doi.org/10.1002/qj.2791.

_ , V. T. J. Phillips, and S. Dobbie, 2016b: Aerosol indirect effects on glaciated clouds. Part 2: Sensitivity tests using solute aerosols. Quart. J. Roy. Meteor. Soc., 142, 1970-1981, https:// doi.org/10.1002/qj.2790

Kumari, B. P., and B. N. Goswami, 2010: Seminal role of clouds on solar dimming over the Indian monsoon region. Geophys. Res. Lett., 37, L06703, https://doi.org/10.1029/2009GL042133.

Li, Z., and Coauthors, 2016: Aerosol and monsoon climate interactions over Asia. Rev. Geophys., 54, 866-929, https:// doi.org/10.1002/2015RG000500.

Lohmann, U., and G. Lesins, 2002: Stronger constraints on the anthropogenic indirect aerosol effect. Science, 298, 1012-1015, https://doi.org/10.1126/science.1075405.

— view. Atmos. Chem. Phys., 5, 715-737, https://doi.org/10.5194/ acp-5-715-2005.

Manara, V., M. Brunetti, A. Celozzi, M. Maugeri, A. SanchezLorenzo, and M. Wild, 2016: Detection of dimming/brightening in Italy from homogenized all-sky and clear-sky surface solar radiation records and underlying causes (1959-2013).
Atmos. Chem. Phys., 16, 11 145-11 161, https://doi.org/10.5194/ acp-16-11145-2016.

- — - M. Maugeri, A. Sanchez-Lorenzo, and M. Wild, 2017: Sunshine duration and global radiation trends in Italy (19592013): To what extent do they agree? J. Geophys. Res., 122, 4312-4331, https://doi.org/10.1002/2016JD026374.

McFarquhar, G. M., and Coauthors, 2011: Indirect and SemiDirect Aerosol Campaign: The impact of Arctic aerosols on clouds. Bull. Amer. Meteor. Soc., 92, 183-201, https://doi.org/ 10.1175/2010BAMS2935.1.

Muneer, T., 2004: Solar Radiation and Daylight Models. Routledge, $345 \mathrm{pp}$.

Norris, J. R., and M. Wild, 2009: Trends in aerosol radiative effects over China and Japan inferred from observed cloud cover, solar "dimming," and solar "brightening." J. Geophys. Res., 114, D00D15, https://doi.org/10.1029/2008JD011378.

Ohmura, A., and Coauthors, 1998: Baseline Surface Radiation Network (BSRN/WCRP): New precision radiometry for climate research. Bull. Amer. Meteor. Soc., 79, 2115-2136, https://doi.org/ 10.1175/1520-0477(1998)079<2115:BSRNBW>2.0.CO;2.

Peterson, T. C., and D. Easterling, 1994: Creation of homogeneous composite climatological reference series. Int. J. Climatol., 14, 671-679, https://doi.org/10.1002/joc.3370140606.

Pinker, R. T., B. Zhang, and E. G. Dutton, 2005: Do satellites detect trends in surface solar radiation? Science, 308, 850-854, https://doi.org/10.1126/science.1103159.

Qian, Y., D. P. Kaiser, L. R. Leung, and M. Xu, 2006: More frequent cloud-free sky and less surface solar radiation in China from 1955 to 2000. Geophys. Res. Lett., 33, L01812, https:// doi.org/10.1029/2005GL024586.

— W. Wang, L. R. Leung, and D. P. Kaiser, 2007: Variability of solar radiation under cloud-free skies in China: The role of aerosols. Geophys. Res. Lett., 34, L12804, https://doi.org/ 10.1029/2006GL028800.

Qiu, Y., C. Zhao, J. Guo, and J. Li, 2017: 8-year ground-based observational analysis about the seasonal variation of the aerosol-cloud droplet effective radius relationship at SGP site. Atmos. Environ., 164, 139-146, https://doi.org/10.1016/j. atmosenv.2017.06.002.

Quaas, J., B. Stevens, P. Stier, and U. Lohmann, 2010: Interpreting the cloud cover-aerosol-optical depth relationship found in satellite data using a general circulation model. Atmos. Chem. Phys., 10, 6129-6135, https://doi.org/10.5194/acp-106129-2010

Ruckstuhl, C., R. Philipona, J. Morland, and A. Ohmura, 2007: Observed relationship between surface specific humidity, integrated water vapor, and longwave downward radiation at different altitudes. J. Geophys. Res., 112, D03302, https:// doi.org/10.1029/2006JD007850.

Sanchez-Lorenzo, A., J. Calbó, and M. Wild, 2013: Global and diffuse solar radiation in Spain: Building a homogeneous dataset and assessing their trends. Global Planet. Change, 100, 343-352, https://doi.org/10.1016/j.gloplacha.2012.11.010.

, M. Wild, M. Brunetti, J. A. Guijarro, M. Z. Hakuba, J. Calbó, S. Mystakidis, and B. Bartok, 2015: Reassessment and update of long-term trends in downward surface shortwave radiation over Europe (1939-2012). J. Geophys. Res. Atmos., 120, 95559569, https://doi.org/10.1002/2015JD023321.

Shi, G. Y., 2007: Atmospheric Radiation. China Science Publishing \& Media Ltd, 402 pp.

, T. Hayasaka, A. Ohmura, Z.-H. H. Chen, B. Wang, J.-Q. Q. Zhao, H.-Z. Z. Che, and L. I. Xu, 2008: Data quality assessment and the long-term trend of ground solar radiation in 
China. J. Appl. Meteor. Climatol., 47, 1006-1016, https:// doi.org/10.1175/2007JAMC1493.1.

Shi, X., and X. Xu, 2006: The spatial characteristics of decadally climatic turnover pattern in winter and summer over China. Chin. Sci. Bull., 51, 2075-2084.

Sogacheva, L., and Coauthors, 2018: Spatial and seasonal variations of aerosols over China from two decades of multi-satellite observations-Part I: ATSR (1995-2011) and MODIS C6.1 (2000-2017). Atmos. Chem. Phys., 18, 11389-11 407, https:// doi.org/10.5194/acp-18-11389-2018.

Stanhill, G., 2005: Global dimming: A new aspect of climate change. Weather, 60, 11-14, https://doi.org/10.1256/wea.210.03.

dence for a widespread and significant reduction in global radiation with discussion of its probable causes and possible agricultural consequences. Agric. For. Meteor., 107, 255-278, https://doi.org/10.1016/S0168-1923(00)00241-0.

Stephens, G. L., and Coauthors, 2002: The Cloudsat mission and the A-Train: A new dimension of space-based observations of clouds and precipitation. Bull. Amer. Meteor. Soc., 83, 17711790, https://doi.org/10.1175/BAMS-83-12-1771.

Tang, W. J., K. Yang, J. He, and J. Qin, 2010: Quality control and estimation of global solar radiation in China. Sol. Energy, 84, 466-475, https://doi.org/10.1016/j.solener.2010.01.006.

,-- J. Qin, C. C. K. Cheng, and J. He, 2011: Solar radiation trend across China in recent decades: A revisit with qualitycontrolled data. Atmos. Chem. Phys., 11, 393-406, https:// doi.org/10.5194/acp-11-393-2011.

Vincent, L. A., X. Zhang, B. R. Bonsal, and W. D. Hogg, 2002: Homogenization of daily temperatures over Canada. J. Climate, 15, 1322-1334, https://doi.org/10.1175/1520-0442(2002)015<1322: HODTOC $>2.0 . \mathrm{CO} ; 2$.

Wan, H., X. L. Wang, and V. R. Swail, 2010: Homogenization and trend analysis of Canadian near-surface wind speeds. J. Climate, 23, 1209-1225, https://doi.org/10.1175/2009JCLI3200.1.

Wang, K., R. E. Dickinson, and S. Liang, 2009: Clear sky visibility has decreased over land globally from 1973 to 2007. Science, 323, 1468-1470, https://doi.org/10.1126/science.1167549.

,$- \ldots$, M. Wild, and S. Liang, 2012: Atmospheric impacts on climatic variability of surface incident solar radiation. Atmos. Chem. Phys., 12, 9581-9592, https://doi.org/10.5194/acp-129581-2012.

,,-- Q. Ma, J. A. Augustine, and M. Wild, 2013: Measurement methods affect the observed global dimming and brightening. J. Climate, 26, 4112-4120, https://doi.org/10.1175/ JCLI-D-12-00482.1.

, Q. Ma, Z. Li, and J. Wang, 2015: Decadal variability of surface incident solar radiation over China: Observations, satellite retrievals, and reanalyses. J. Geophys. Res., 120, 6500-6514, https://doi.org/10.1002/2015JD023420.

Wang, X. L., 2008: Penalized maximal F test for detecting undocumented mean shift without trend change. J. Atmos. Oceanic Technol., 25, 368-384, https://doi.org/10.1175/2007JTECHA982.1.

— , and Y. Feng, 2013: RHtests V4.0 user manual. Environment Canada, 29 pp., etccdi.pacificclimate.org/RHtest/RHtestsV4_ UserManual_20July2013.pdf.

$\longrightarrow$, Q. H. Wen, and Y. Wu, 2007: Penalized maximal $t$ test for detecting undocumented mean change in climate data series. J. Appl. Meteor. Climatol., 46, 916-931, https://doi.org/10.1175/JAM2504.1. , H. Chen, Y. Wu, Y. Feng, and Q. Pu, 2010: New techniques for the detection and adjustment of shifts in daily precipitation data series. J. Appl. Meteor. Climatol., 49, 2416-2436, https:// doi.org/10.1175/2010JAMC2376.1.
, Y. Feng, and L. A. Vincent, 2014: Observed changes in onein-20 year extremes of Canadian surface air temperatures. Atmos.-Ocean, 52, 222-231, https://doi.org/10.1080/07055900. 2013.818526.

Wang, Y., and M. Wild, 2016: A new look at solar dimming and brightening in China. Geophys. Res. Lett., 43, 11777-11 785, https://doi.org/10.1002/2016GL071009.

Wild, M., 2009: Global dimming and brightening: A review. J. Geophys. Res., 114, D00D16, https://doi.org/10.1029/ 2008JD011470.

_ 2012: Enlightening global dimming and brightening. Bull. Amer. Meteor. Soc., 93, 27-37, https://doi.org/10.1175/BAMSD-11-00074.1.

_- , and Coauthors, 2005: From dimming to brightening: Decadal changes in solar radiation at Earth's surface. Science, 308, 847-850, https://doi.org/10.1126/science. 1103215.

Winker, D. M., M. A. Vaughan, A. Omar, Y. Hu, K. A. Powell, Z. Liu, W. H. Hunt, and S. A. Young, 2009: Overview of the CALIPSO mission and CALIOP data processing algorithms. J. Atmos. Oceanic Technol., 26, 2310-2323, https://doi.org/ 10.1175/2009JTECHA1281.1.

Wu, J., J. Luo, L. Zhang, L. Xia, D. Zhao, and J. Tang, 2014: Improvement of aerosol optical depth retrieval using visibility data in China during the past 50 years. J. Geophys. Res. Atmos., 119, 13370-13387, https://doi.org/10.1002/ 2014JD021550.

Xu, W., Q. Li, X. Wang, S. Yang, L. Cao, and Y. Feng, 2013: Homogenization of Chinese daily surface air temperatures and analysis of trends in the extreme temperature indices. J. Geophys. Res., 118, 9708-9720, https://doi.org/10.1002/ jgrd.50791.

Yang, S., G. Y. Shi, B. Wang, and D. Li, 2013: Trends in surface solar radiation (SSR) and the effect of clouds on SSR during 1961-2009 in China (in Chinese). Chin. J. Atmos. Sci., 37, $963-$ 970.

- X. L. Wang, and M. Wild, 2018: Homogenization and trend analysis of the 1958-2016 in situ surface solar radiation records in China. J. Climate, 31, 4529-4541, https://doi.org/10.1175/ JCLI-D-17-0891.1.

Yang, X., C. Zhao, J. Guo, and Y. Wang, 2016a: Intensification of aerosol pollution associated with its feedback with surface solar radiation and winds in Beijing. J. Geophys. Res., 121, 4093-4099, https://doi.org/10.1002/2015JD024645.

,-- L. L. Zhou, Y. Wang, and X. Liu, 2016b: Distinct impact of different types of aerosols on surface solar radiation in China. J. Geophys. Res., 121, 6459-6471, https://doi.org/10.1002/ 2016JD024938.

,,,--- Z. Li, M. Cribb, and S. Yang, 2018: Wintertime cooling and a potential connection with transported aerosols in Hong Kong during recent decades. Atmos. Res., 211, 52-61, https://doi.org/10.1016/j.atmosres.2018.04.029.

Yu, H., and Coauthors, 2006: A review of measurement-based assessments of the aerosol direct radiative effect and forcing. Atmos. Chem. Phys., 6, 613-666, https://doi.org/10.5194/acp-6613-2006.

Zhang, X., G. Hegerl, F. W. Zwiers, and J. Kenyon, 2005: Avoiding inhomogeneity in percentile-based indices of temperature extremes. J. Climate, 18, 1641-1651, https://doi.org/10.1175/ JCLI3366.1.

Zhao, C., and T. J. Garrett, 2015: Effects of Arctic haze on surface cloud radiative forcing. Geophys. Res. Lett., 42, 557-564, https://doi.org/10.1002/2014GL062015. 
- S. A. Klein, S. Xie, X. Liu, J. S. Boyle, and Y. Zhang, 2012: Aerosol first indirect effects on non-precipitating low-level liquid cloud properties as simulated by CAM5 at ARM sites. Geophys. Res. Lett., 39, L08806, https://doi.org/10.1029/ 2012 GL051213.

-, Y. Qiu, X. Dong, Z. Wang, Y. Peng, B. Li, Z. Wu, and Y. Wang, 2018: Negative aerosol-cloud $r_{e}$ relationship from aircraft observations over Hebei, China. Earth Space Sci., 5, 19-29, https://doi.org/10.1002/2017EA000346.

Zheng, C., and Coauthors, 2018: Spatial and temporal distribution of $\mathrm{NO}_{2}$ and $\mathrm{SO}_{2}$ in Inner Mongolia urban agglomeration obtained from satellite remote sensing and ground observations. Atmos. Environ., 188, 50-59, https://doi.org/10.1016/ j.atmosenv.2018.06.029.

Zhou, X., A. S. Ackerman, A. M. Fridlind, R. Wood, and P. Kollias, 2017: Impacts of solar-absorbing aerosol layers on the transition of stratocumulus to trade cumulus clouds. Atmos. Chem. Phys., 17, 12 725-12 742, https://doi.org/10.5194/acp-17-127252017.

Zhu, Y., L. Cao, G. Tang, and Z. Zhou, 2015: Homogenization of surface relative humidity over China (in Chinese). Climate Change Res., 11, 379-386. 